\title{
Competition of trade and investment between Guangzhou and BRI countries: an empirical analysis based on Export Similarity Index
}

\author{
Xiaofei Luo ${ }^{1}$, Yonghui Han ${ }^{2, a}$ and Fan Zhang ${ }^{3}$ \\ ${ }^{1}$ Faculty of Logistics, Guangdong Mechanical and Electrical Technical College, Guangzhou, Guangdong510515, China \\ ${ }^{2}$ Guangdong Institute for International Strategies, Guangdong University of Foreign Studies, Guangzhou, Guangdong510420, China \\ ${ }^{3}$ Rajaratnam School of International Studies, Nanyang Technological University639798, Singapore
}

\begin{abstract}
Trade and investment are significant aspects in economic cooperation between Guangzhou and BRI (Belt and Road Initiative) countries. To solve its economic dilemma in export and manufacturing sector, Guangzhou should try to identify the BRI regions to promote overseas production capacity cooperation, especially in trade and investment. By dividing the BRI countries into six regional groups and using a modified ESI (Export Similarity Index) model, this paper aims to examine the level of competition between Guangzhou and various BRI regional groups from perspectives of trade and investment. From the results, we find that Guangzhou has the highest competition level with ASEAN and South Asian countries in trade while in investment, ASEAN and Central and Eastern Europe are the most potent competitors for Guangzhou. We think there are insightful implications within the empirical analysis and could promote the efficiency of Guangzhou's trade and outward investment under the BRI framework.
\end{abstract}

\section{Introduction}

Since Deng Xiaoping implemented the Reform and Opening-up Policy in China, Guangzhou has made tremendous economic achievement by taking advantages of its low production factor cost and convenient transportation. For years, the export growth rate of Guangzhou has maintained double digits. Nevertheless, with the gradual increase of production cost, as well as the raised threshold of corporate financing, the cost of foreign trade in Guangzhou keeps climbing. The emergence of new competitors either from domestic market (Mid-West China) or abroad, like Vietnam and Laos, are also challenging Guangzhou's advantages in low cost. The rocketing cost of export and plummeting export orders force abundance of corporate to reduce their production, and some even bankrupt. In 2014, the growth rate of export in Guangzhou was around $15.8 \%$. The figure dropped to $12.7 \%$ in 2015 and even plunged precipitously to $3 \%$ in 2016 . If we look at the overall export of China, we could find that it is also experiencing a shift from high-speed growth to a much slower one. The trade of labor-intensive industry is declining dramatically and contracts to negative growth. Although general trade is increasing rapidly, its scale is not impressive enough to be the locomotive of the entire trade development. Thanks to the loss of advantages in low-cost production, the stagnation of economy seems inevitable.

However, the opportunity lies within the BRI (Belt and Road Initiative). With the elimination of trade barriers and the increase of investment under the BRI, strengthening the "production capacity cooperation" between Guangzhou and BRI countries becomes a viable while important option. When considering production capacity cooperation, trade and investment are the two most significant aspects because the ease of trade and investment plays an indispensable role in promoting economic relationship. By tightening economic ties with BRI countries, primarily through trade and investment, Guangzhou would be able to transfer its low-end capacity to suitable regions, and further upgrade its industrial structure, which would be a promising alternative for the traditional way of economic development. Thus, to improve the production capacity cooperation between Guangzhou and BRI countries, we think it is essential to analyze the level of competition between them. This essay aims to study the level of competition between Guangzhou and BRI countries from two perspectives, which are trade and investment. We use a modified ESI model to estimate the similarity of trade and investment behavior between Guangzhou and BRI countries. After concluding the research, we provide insightful policy recommendations.

\section{Model, Methodology, and Data}

Finger et al. (1979) [1] is the first to introduce the method of measuring similarity in the commodity area. Later Glick and Rose (1999) [2] used similarity index in 
the market area. The variation in ESI (Export Similarity Index) could reflect the features of economic development, the evolution of industrial structure, and the process of industrialization in the given regions.

\subsection{Model and Methodology}

We use the theory of the ESI model, set up by Glick and Rose (1999) [2], for reference in our research. Based on the theory, we design the similarity index of trade and investment for Guangzhou and BRI countries. The formula is :

$$
S(m n, a)=\left\{\sum_{i=1}^{N} \min i m u m\left[X_{i}(a c), X_{i}(b c)\right]\right\}
$$

$X_{i}{ }^{(a c)}$ and $X_{i}{ }^{(b c)}$, respectively, represents the share of commodities i imported by country c from country a, or country b, to country c's total trade amount. This formula has been widely used in China (Zong, 2006; Zhang and Cai, 2008) [3, 4]. Considering the problem of deviation testing, Shi (2003) [5] further modified the formula, making it possible to be applied in subdivided sectors:

$$
E S I_{a b}=\left\{\sum_{i=0}^{n}\left[\left(\frac{X_{a k}^{i} / X_{a k}+X_{b k}^{i} / X_{b k}}{2}\right) \cdot\left(1-\frac{X_{a k}^{i} / X_{a k}-X_{b k}^{i} / X_{b k}}{X_{a k}^{i} / X_{a k}+X_{b k}^{i} / X_{b k}}\right)\right]\right\} \times 100
$$

In this formula, $a$ and $b$, respectively, represent region a and region b; k means third-party market. $X_{a k}^{i} / X_{a k}$ represents the percentage of commodities $i$ exported to market $\mathrm{k}$ by region a in the total trade volume between region a and market k. $X_{b k}^{i} / X_{b k}$ represents the share of commodities $\mathrm{i}$ exported to market $\mathrm{k}$ by region $\mathrm{b}$ to the total trade amount between region $\mathrm{b}$ and market $\mathrm{k}$. The range of $E S I_{a b}$ is [0,100]. The higher the ESI, the more similar the commodity export structure of region a and region $\mathrm{b}$, and therefore, the more intensive the competition between region $\mathrm{a}$ and $\mathrm{b}$. The lower the index, the less the similarity and the less competition between region a and $b$. An increase of ESI over time indicates that the export structures of region $a$ and $b$ are overlapping, which means the two regions would face more fierce competition in the future in market $\mathrm{k}$. Likewise, we could also apply this method in examining the similarity of international investment between regions. In this case, $X_{a k}^{i} / X_{a k}$ represents the share of investment to commodity $\mathrm{i}$ from region a in market $\mathrm{k}$ to the total investment from region a in market k. $X_{b k}^{i} / X_{b k}$ represents the share of investment to commodity i from region $\mathrm{b}$ in market $\mathrm{k}$ to the total investment from region $\mathrm{b}$ in market $\mathrm{k}$. As the similarity index rises, the investment structure of region $\mathrm{a}$ and $\mathrm{b}$ would be more similar (in market k), and consequently, the competition between the two regions is more intense.

In our research, we use this modified ESI model and analyze the similarity of trade and investment between Guangzhou and BRI countries in the context of the world market.

\subsection{Data}

The data of Guangzhou comes from Guangzhou Statistical Yearbook, Guangdong Statistical Yearbook, China Customs Data, and related databases. The data of BRI countries is extracted from WTO and UN Comtrade Database. Among all the BRI countries, we select 65 countries as research samples. These countries are categorized into six various regional groups (ASEAN countries, East Asia, West Asia, Central Asia, CIS countries and Central and Eastern Europe) based on Statistical Bulletin of China's Outward Foreign Direct Investment (Table 1). The time chosen in this study ranges from 1995 to 2014 .

\begin{tabular}{|c|c|}
\hline Region & Country \\
\hline East Asia (1) & Mongolia \\
\hline $\begin{array}{l}\text { ASEAN } \\
\text { Countries (10) }\end{array}$ & $\begin{array}{l}\text { Singapore, Malaysia, Indonesia, } \\
\text { Myanmar, Thailand, Laos, Cambodia, } \\
\text { Vietnam, Brunei, Philippines }\end{array}$ \\
\hline West Asia (18) & $\begin{array}{l}\text { Iran, Iraq, Turkey, Syria, Jordan, } \\
\text { Lebanon, Israel, Palestine, Saudi Arabia, } \\
\text { Yemen, Oman, UAE, Qatar, Kuwait, } \\
\text { Bahrain, Greece, Cyprus, Egypt }\end{array}$ \\
\hline South Asia (8) & $\begin{array}{l}\text { India, Pakistan, Bangladesh, } \\
\text { Afghanistan, Sri Lanka, Maldives, } \\
\text { Nepal, Bhutan }\end{array}$ \\
\hline $\begin{array}{l}\text { Central Asia } \\
(5)\end{array}$ & $\begin{array}{l}\text { Kazakhstan, Uzbekistan, Turkmenistan, } \\
\text { Tajikistan, Kyrghyzstan }\end{array}$ \\
\hline $\begin{array}{l}\text { CIS Countries } \\
(7)\end{array}$ & $\begin{array}{l}\text { Russia, Ukraine, Belarus, Georgia, } \\
\text { Azerbaijan, Armenia, Moldova }\end{array}$ \\
\hline $\begin{array}{l}\text { Central and } \\
\text { Eastern Europe } \\
(16)\end{array}$ & $\begin{array}{l}\text { Poland, Lithuania, Estonia, Latvia, } \\
\text { Czech, Slovakia, Hungary, Slovenia, } \\
\text { Croatia, Bosnia and Herzegovina, } \\
\text { Montenegro, Serbia, Albania, Romania, } \\
\text { Bulgaria, Macedonia }\end{array}$ \\
\hline
\end{tabular}

Table 1. Selected BRI countries and regions.

\section{Empirical Results}

\subsection{Trade}

The analysis result of trade similarity between Guangzhou and BRI countries is presented in Table 2. At a glance, we could find out that since 1995 the similarity index of export structure between Guangzhou and BRI countries has been at a relatively high level, showing a steady trend of growing chronologically.

To be more specific, the ESI is the highest between Guangzhou and ASEAN countries. The index climbed from 76.19 in 1995 to 80.14 in 2014, indicating a highly similar export structure and high level of competition between Guangzhou and ASEAN countries. We could predict that the tension would likely to escalate in the future. BRI countries in South Asia come the second. The similarity index between them and Guangzhou floated between 63.73 and 70.22. We think this high ESI between Guangzhou, ASEAN countries, and South Asian countries could be explained by their convergent focus on labor-intensive industry in their economic development. On the other hand, the ESI between Guangzhou and Central and Eastern Europe keeps declining over time and gradually sticks around 55, revealing that the level of competition in export is 
becoming moderate and the production capacity of the two regions is becoming complementary. Guangzhou has the lowest ESI in Central Asia, West Asia, and CIS countries. From 1995 to 2014, the index has maintained a low level regularly, with Central Asia at 36.56-46.53, West Asia at 33.73-40.22, and CIS countries at 31.51-55.73. As the profitability of energy sector decreases in recent years, we assume that the traditional economic locomotive of Central Asia and West Asia countries, which is crude oil and natural gas export, could not sustain the speed it used to reach. The problems in these regions, however, imply substantial opportunities for Guangzhou in production capacity cooperation. As for CIS countries, the index has been increasing gradually over time, suggesting a gradual re-industrialization after the collapse of Soviet Union. However, this regains of competitiveness of CIS countries should not be a concern for Guangzhou since the index still maintains at a low level.

To conclude, Guangzhou has a high level of competition with ASEAN countries and South Asian countries while it has a relatively low level of competition with Central and Eastern Europe, Central Asia, West Asia, and CIS countries. Over time, the competition between Guangzhou and Central and Eastern Europe is alleviating. However, the gross level of competition in trade is escalating across the BRI countries.

Table 2. Trade similarity index of selected BRI regions.

\begin{tabular}{|c|c|c|c|c|c|c|c|}
\hline Year & Total & ASEAN & West Asia & $\begin{array}{c}\text { Central } \\
\text { Asia }\end{array}$ & South Asia & CIS & $\begin{array}{c}\text { Central and } \\
\text { Eastern Europe }\end{array}$ \\
\hline 1995 & 47.03 & 76.19 & 33.73 & 35.56 & 63.73 & 34.97 & 59.95 \\
\hline 1996 & 48.11 & 77.22 & 34.54 & 34.45 & 64.54 & 36.01 & 62.31 \\
\hline 1997 & 51.96 & 74.79 & 38.84 & 35.71 & 68.84 & 33.38 & 58.62 \\
\hline 1998 & 51.31 & 77.97 & 36.34 & 43.66 & 66.34 & 43.19 & 63.81 \\
\hline 1999 & 51.75 & 76.64 & 29.18 & 41.11 & 59.18 & 36.82 & 58.79 \\
\hline 2000 & 56.08 & 80.23 & 35.52 & 42.11 & 65.52 & 40.57 & 59.63 \\
\hline 2001 & 61.42 & 87.89 & 38.14 & 41.94 & 68.14 & 47.86 & 64.30 \\
\hline 2002 & 61.96 & 89.13 & 36.13 & 42.01 & 66.13 & 52.31 & 63.89 \\
\hline 2003 & 65.59 & 82.62 & 41.47 & 41.12 & 71.47 & 55.73 & 62.21 \\
\hline 2004 & 66.91 & 84.64 & 37.82 & 43.73 & 67.82 & 54.25 & 58.19 \\
\hline 2005 & 68.38 & 83.73 & 40.35 & 49.87 & 70.35 & 43.70 & 56.80 \\
\hline 2006 & 68.71 & 82.07 & 44.19 & 49.31 & 74.19 & 41.12 & 55.11 \\
\hline 2007 & 68.87 & 88.54 & 34.75 & 45.22 & 64.75 & 40.30 & 55.31 \\
\hline 2008 & 69.69 & 82.79 & 43.20 & 40.00 & 73.20 & 37.50 & 54.43 \\
\hline 2009 & 69.86 & 87.08 & 42.33 & 42.52 & 72.33 & 40.66 & 55.17 \\
\hline 2010 & 62.69 & 86.98 & 37.28 & 42.28 & 67.28 & 37.89 & 55.41 \\
\hline 2011 & 63.11 & 89.58 & 37.58 & 49.78 & 67.58 & 31.51 & 54.86 \\
\hline 2012 & 66.44 & 80.28 & 36.73 & 43.49 & 66.73 & 42.16 & 53.75 \\
\hline 2013 & 60.69 & 78.69 & 39.16 & 42.77 & 69.16 & 46.02 & 53.69 \\
\hline 2014 & 64.42 & 80.14 & 40.22 & 46.53 & 70.22 & 47.00 & 56.15 \\
\hline AVG & 61.25 & 82.36 & 37.88 & 42.66 & 67.88 & 42.15 & 58.12 \\
\hline
\end{tabular}

\subsection{Investment}

The analysis result of investment similarity between Guangzhou and BRI countries is presented in Table 3. Overall, the investment similarity index between Guangzhou and BRI countries is at a medium level, which is around 50. Among the six regions, Guangzhou has the highest level of similarity with ASEAN countries, which keeps swinging between 70 and 80 during the 20 years. CIS countries rank the second with an average index at 69.22. Central and Eastern Europe and South Asia come the next, and the indexes average at 63.64 and 61.29, which is at a medium-high level. Central Asia, as well as West Asia, has relatively low indexes, averaging 30 and 40 respectively between 1995 and 2014. Through a dynamic perspective, Guangzhou has a stable relationship with all the BRI countries. However, the indexes between Guangzhou and Central Asia, West Asia, and CIS countries are suggesting a declining tendency, which means a more complementary relationship in the investment market.

As a conclusion, the level of competition in investment is the highest between Guangzhou and ASEAN countries, CIS countries and Central and Eastern Europe, while it is relatively lower between Guangzhou and Central Asia, West Asia and South Asia. During the 20 years, the competition in investment between Guangzhou and Central Asia, West Asia, and CIS countries is moderating.

Table 3. Investment similarity index of selected BRI regions.

\begin{tabular}{|c|c|c|c|c|c|c|c|}
\hline Year & Total & ASEAN & West Asia & $\begin{array}{c}\text { Central } \\
\text { Asia }\end{array}$ & South Asia & CIS & $\begin{array}{c}\text { Central and } \\
\text { Eastern Europe }\end{array}$ \\
\hline 1995 & 53.10 & 73.86 & 44.67 & 34.76 & 63.19 & 77.98 & 65.84 \\
\hline 1996 & 52.25 & 74.41 & 43.48 & 30.80 & 63.40 & 77.33 & 65.57 \\
\hline 1997 & 51.96 & 75.16 & 42.44 & 31.22 & 62.96 & 76.23 & 65.64 \\
\hline 1998 & 52.09 & 75.53 & 42.63 & 31.86 & 62.88 & 76.06 & 65.68 \\
\hline
\end{tabular}




\begin{tabular}{|l|l|l|l|l|l|l|l|}
\hline 1999 & 51.71 & 75.94 & 42.25 & 31.74 & 62.64 & 76.93 & 64.09 \\
\hline 2000 & 51.37 & 70.70 & 41.93 & 34.34 & 62.63 & 70.70 & 63.80 \\
\hline 2001 & 51.65 & 74.88 & 42.58 & 35.51 & 62.09 & 72.94 & 64.11 \\
\hline 2002 & 51.39 & 76.70 & 42.35 & 34.26 & 62.70 & 72.71 & 63.30 \\
\hline 2003 & 51.57 & 71.46 & 42.37 & 34.83 & 62.53 & 71.46 & 63.23 \\
\hline 2004 & 51.60 & 77.09 & 42.13 & 35.20 & 62.66 & 74.06 & 63.33 \\
\hline 2005 & 51.33 & 76.75 & 41.93 & 34.40 & 62.93 & 72.80 & 63.42 \\
\hline 2006 & 51.14 & 76.64 & 41.72 & 33.56 & 62.97 & 72.34 & 63.45 \\
\hline 2007 & 53.78 & 66.84 & 41.66 & 31.82 & 61.84 & 66.84 & 62.96 \\
\hline 2008 & 53.35 & 65.20 & 45.20 & 29.43 & 60.20 & 65.20 & 62.24 \\
\hline 2009 & 52.79 & 66.64 & 42.64 & 29.38 & 57.64 & 62.64 & 61.34 \\
\hline 2010 & 52.81 & 61.91 & 41.91 & 30.13 & 56.91 & 61.91 & 61.91 \\
\hline 2011 & 52.96 & 63.15 & 43.15 & 29.23 & 58.15 & 63.15 & 62.74 \\
\hline 2012 & 52.73 & 68.91 & 41.91 & 27.87 & 56.91 & 61.91 & 61.91 \\
\hline 2013 & 50.20 & 75.20 & 37.20 & 28.96 & 59.20 & 57.20 & 64.20 \\
\hline 2014 & 51.04 & 71.34 & 38.04 & 28.83 & 61.31 & 54.04 & 64.08 \\
\hline AVG & 52.04 & 71.92 & 42.11 & 31.91 & 61.29 & 69.22 & 63.64 \\
\hline
\end{tabular}

\section{Conclusion and Implications}

Our research focuses on the level of competition between Guangzhou and BRI countries in trade and investment. It is one of the few studies that put the city-level trade and investment in the BRI context. By using a modified ESI model, we reveal several new findings.

Regarding trade, Guangzhou has the highest level of competition with ASEAN countries and South Asian countries while Central Asia and West Asia are the lowest. The one between Guangzhou and Central and Eastern Europe is being alleviated noticeably over the years. In investment, Guangzhou has the highest level of competition with ASEAN countries and Central and Eastern Europe while the one with Central Asia and West Asia is comparatively lower.

International economy has been sluggish for years after the 2008 Global Financial Crisis. Due to the contraction of foreign demand, the prevalence of protectionism, and Guangzhou's overly dependence on export, the manufacturing sector in Guangzhou is facing an economic "perfect storm," suffering from an exacerbated market and stagnation of technological development. However, according to our empirical results, there is a feasible solution. Although Guangzhou is losing advantages in low-cost manufacturing sectors when competing with ASEAN and South Asian countries, its production capacity structure is becoming more complementary with Central and West Asian countries. Guangzhou should re-design its trade and investment policy based on this new change. We recommend that Guangzhou should seek the first breakthrough in low value-added industries with overcapacity by transferring them to suitable BRI countries, like Central Asia and West Asia. In the meantime, Guangzhou should explore more capacity cooperation opportunities with developed countries and regions through the "Going Out" and "Bringing In" strategies.

This work is partially supported by Key Grant Projects of Philosophy and Social Sciences Research, Ministry of Education of China (Grant No.16JZD018). Yonghui Han is the corresponding author, the e-mail is hanyonghui2006@foxmail.com.

\section{References}

1. J. M. Finger, M. E. Kreinin, ECON J 89, 905-912(1979).

2. R Glick, A. K. Rose, J INT MONEY FINANC 18, 603-617(1999).

3. Y. Zong, Industrial Economics Research 1, 17-25(2012).

4. C. Zhang, X. Cai, Journal of International Trade 1, 109-114(2008).

5. Z. Shi, Finance and Trade Economics 9, 53-57(2009). 